\title{
Current and Future Regulation Challenges for the Chinese Telecommunications Sector
}

\author{
Ning He \\ School of Economics and management, Xi' an Institute of Post \& Telecoms \\ 536 South of Chang'An Road, Xi'an 710061, China \\ E-mail: hening915@126.com
}

\begin{abstract}
For Chinese telephony, the new restructuring scheme - designed to boost efficiency and create three full-service operators is completed by the end 2008. This paper studies the regulatory trajectory of the telecommunications industry in China. Different stages of the regulation process with policy intervention and market competition are examined. The interaction of different players like the Chinese government, incumbent operator, and competitive operator is analyzed. In the paper, two general theories of regulation, public interest theory and the economic theory of regulation are firstly introduced. Theses literatures are later used to explain the current regulatory particularities of Chinese telephony.
\end{abstract}

Keywords: Telecommunications, Natural monopoly, Legislation, The Significant Market Power (SMP), Ex ante and ex post regulation

Historically, two general theories of regulation have been developed to explain the regulation of telecom markets. The first of these, called the public interest theory, argues that the reason for regulation is to avoid market failure when an industry is naturally monopolistic. This theory presumes that the goal of regulation is to simulate competition where it is allegedly impossible because of economies of scale, and that this intention will, in fact, be carried out by the regulatory process. The second approach, popularized by Stigler and Peltzman is the economic theory of regulation (John T. Wenders, 1988). The essence of this approach is that regulators and politicians, like economic men, weigh the benefits and costs of various courses of action in a political framework where the attainment of a voting majority determines success.

To better appreciate the dynamics of the telecom sector regulation, it is helpful to think in terms of three generations of telecommunications (Eli M. Noama, 2010). The first generation of Telecom was the traditional monopoly system, state owned, or tightly regulated. Technologically it was based on copper analog networks. Culturally it was shaped by an engineering and state bureaucracy. After the 1980s this first-generation system was transformed into a more open structure with liberalized entry, especially in wireless, privatized incumbents, and accelerating innovation. The second generation of Telecom is based on the concept of deregulation. Competition leads to innovation and enables deregulation. Government intervention, let alone ownership, is the problem to be overcome. This became the orthodoxy. But this was not the end of history in telecommunications. Technology took another major step forward, this time focused on fiber-optic and high-capacity wireless access networks. Whereas the first-generation created networks that operated at kilobit per second transmission capacity, the second-generation reached mass consumer operations in the broadband megabit range, almost a thousand times as fast. And the third-generation will operate at another thousand-fold increase in speed in the gigabit range.

The starting point of this paper was a research interest in transformed statehood in the Chinese telecommunications regulation, under the influence of liberalization, privatization, globalization and convergence. A central point in this paper is that Chinese regulatory practice may need a drastic overhaul in order to be able to accept convergence.

\section{Regulation literature review}

\subsection{Market failure requiring government regulation}

Within the social sciences -thinking about regulation often starts with the notion of market failure. In an idealized economic market, individuals maximize the welfare of all simply by pursuing their own self-interest. Sometimes, however, in practice, the invisible hand of the market fails to optimize social welfare. The culprits, economists have taught us, are such things as public goods and externalities, which threaten to drive a wedge between individual and social welfare. Particularly in the 1950s and 1960s, and even into the 1970s, social scientists often regarded market failure as a sufficient justification for government intervention. Negative externalities such as industrial pollution, for example, had to be regulated or taxed. More generally, regulators 
were understood to be engaged in an ongoing search and destroy mission, with market failure as the target.( Edward Balleisen \&David Moss ,2009).

\subsection{Government failure calling for deregulation}

By the late 1970s, social scientists had begun paying more careful attention to the problem of government failure, Policymakers, we learned, were always liable to be captured by special interest groups or otherwise diverted from serving the public interest as a result of weak incentives or ineffective monitoring. And even those policymakers with the best of intentions - and incentives - could fail as a result of inadequate information. So-called command-and-control regulation was seen as particularly vulnerable to information deficiencies since it was thought to run roughshod over the price mechanism, the pivotal purveyor of information in well functioning markets. Although market failure remained an important and much touted concept in the social sciences, government failure increasingly displaced market failure as a dominant subject of study. Article after article in the scholarly literature spotlighted government shortcomings and missteps and the scourge of unintended consequences. Indeed, as skepticism - even cynicism - began to displace optimism in academic thinking about government, pressure mounted in the policy arena for broad-based deregulation. Pushed forward by leading academics, from George Stigler to Alfred Kahn, the movement for deregulation reflected a profound shift in the intellectual climate.

In order to overcome the government failure, Competition is a good solution. It limits a government's ability to use regulation to favor certain stakeholders or to sacrifice long term efficiency for short term political goals. It also limits operators' abilities to raise prices and creates opportunities for different firms to try innovative ways to attract customers. There are three basic approaches. The first approach is to have multiple operators compete in the market for customers. This is called competition in the market. The second method, called competition for the market, is to have operators compete for the market by having the operators bid for the right to be a service provider. The third technique is to have operators in different markets compete by comparing the efficiency and effectiveness of their operations and rewarding those operators that provide superior performance (Mark A. Jamison \& Mark A. Jamison ,2008).

\section{3 new era of re-regulation}

With the emergence of voice telephony based on the Internet Protocol (VoIP), telecommunications markets are rapidly changing. The application of the Internet Protocol (IP) helps operators to digitize their services in a coordinated fashion. This development, known as convergence, may ultimately lead to a decoupling of services and platforms: any service can be offered over any network. This is a drastic change for the telecommunications sector: incumbents have to adapt to the new reality, and they are challenged by newcomers from unexpected directions, sometimes with very innovative business models.

New forms of inter-modal competition and cooperation are pervasive. Competitive relations between players coexist with strong complementarity relations, resulting in highly complex and dynamic market processes for which ex ante regulatory rules may be difficult to devise (Johannes M. Bauer,2010). Convergence and innovation have strong implications for market structure and competition. As a consequence, these developments must be taken into account by sector-specific regulation and competition policy. This paper explores and discusses the challenges for regulation as imposed by convergence and the emergence of IP-based services, with a focus on innovation and investment incentives. It adopts a Chinese perspective, in the telecommunications sector; an important challenge for regulation is to keep up with technological change and innovation. In the highly complicated environment, regulation to the telephony should not adopt the simple method of command-control regulation, and the deregulation. The telecommunication industry requires some innovative approaches to regulate it effectively.

\section{Chinese telephony historical background}

In recent decades, most countries have initiated telecommunications reforms, these reform manifests divergences in approaches. Being an element in the national economy and political system, telecommunications reform cannot be carried out independently of a macro reform program. For a long period China strictly adhered to a socialist regime that excluded competition. With limited private-owned economic elements as a supplement, the national economy was controlled by state-owned enterprises. In 1978 China entered an era called the "system reform and market opening" (Ping Gao \& Kalle Lyytinen, 2000). The traditional socialist regime began to undergo a series of reforms towards socialism market economy. Hence Chinese reform has been to adopt market economy while maintaining socialism.

In telephony, to avoid political risk, China has employed a reform model one could call "act after trials". This 
means that instead of initializing an overall reform by issuing new laws and completely adjusting the administrative regime, a feasible new system is found through some trials with only limited, necessary modifications on the administrative regime being made. Once the new system has been formally formed, an overall reform is subsequently carried out by enacting state directives and completely reforming administrative regime. Under this principle, while market change has moved forward step by step, administrative reform has advanced laggardly and legislative processes have been carried out slowly compared with practical need.

\section{Recent regulatory practices in china telephony}

\subsection{China "VAP" (the "Village Access Project")}

China commenced launching the "Village Access Project" ("VAP") in 2004 as an interim institutional arrangement in which access tasks are distributed among the incumbent carriers to address the pressing issue of providing basic telephone services to its rural areas (Jun Xia and Ting-Jie Lu, 2008 ). By the end of 2007, China's government has managed to connect roughly $99.5 \%$ of its total administrative villages 4 each with at least two workable telephone lines. In doing so, the six carriers have committed RMB 540 million to extending networks to rural areas by the end of 2006 .As an objective of its contemporary ideology of building a "harmonious" society through a system of "Socialist New Villages" ("SNVs"), the Communist Party of China ("CPC") is currently launching an even more ambitious goal of further promoting telephone penetration as well as Internet diffusion in its vast rural areas. The objective of this drive can be briefly summarized as extending "telephony to every village and broadband to every township" by the end of the 11th Five Year Plan ("FYP"). Political and ideological forces are now inclined to go even further to advocate a new round of large-scale crusades to eventually deploy most ICT services to every corner of rural China. Echoing the call of the CPC's Central Committee, in the early 2006, the former MII promulgated a suggestion which loosely outlines, inter alia, the objectives and administrative measures of the ICT sector's participation in the nationwide SNVs drive.

\subsection{China newly enacted AML (anti monopoly law)}

A new PRC Anti-Monopoly Law (AML) was enacted on August 30, 2007 and took effect on August 1, 2008. Over the last 30 years, economic reforms had been the cornerstone of PRC transformation. Pro-competition law and regulations, in one form or another, were enacted. These regulatory instruments, however, were weak and sporadic and together did not form a comprehensive competition law regime. (Grace $\mathrm{Li}$,2009). Basically, prior to the passage of the AML, Chinese legislation only partially dealt with anti-competitive practices related to market conduct. The Chinese legislature justified the absence of Western typed antitrust regulations by claiming that other Chinese laws such as the Product Quality Act and the Consumer Protection Act protected consumer interests were of a similar nature. Nonetheless, these acts are primarily product liability laws, not antitrust laws.

\subsection{New market restructuring}

The PRC State Council announced its Ministerial Reform Plan on 11th March 2008. The plan specified an establishment of a Ministry of Industry and Information Technology of the People's Republic of China (MIIT) to replace the previous telecommunications regulator MII (The Ministry of Information Industry). In detail, MIIT is established by merging the previous MII, the Commission of Science Technology and Industry for National Defense of the People's Republic of China (COSTIND), the State Council Office of Developing Information Society, and some offices of PRC National Development and Reform Commission (NDRC).

On 24th May 2008, a Notice of Deepening Reform in Telecommunications Sector was published by MII in conjunction with NDRC and National Treasury. The notice specified a new market reform, which included a sale of China Unicom's CDMA network to China Telecom, merging China Unicom to China Netcom, merging China Satellite basic telecommunication business to China Telecom, and merging China Railcom to China Mobile. In simple, this reform merged the previous six telecommunications SOEs into three super-SOEs. It is therefore widely referred to as the 'six to three' reform.

\section{Regulatory challenges in Chinese telecom sector}

\subsection{A critical analysis: problems to the existing regulatory regime:}

Although the current regulatory reform is meant to transform telecom carriers into full market players under effective regulation, the decade-long structural and regulatory reform has resulted in neither genuine competition nor government-business separation. It will be no easy task for China to work out an optimal policy prescription within a short period of time given its drastic regulatory transition, industry consolidation, and general economic and socio-cultural conditions. The fundamental causes for these deficiencies are arguably rooted in China's political foundation, and consequently, the socio-economic and legal system. Current Economic liberalization that has left the fundamental political regime untouched in China has resulted in a specious market economy and 
a skewed institutional environment. The general institutional condition at economy level is doomed to be mirrored at the industry level, as sector-specific institutional characteristics are inevitably pre-determined or substantially influenced by the general institutional environment.

Meanwhile, invisible ties such as the complicated interpersonal relations between the regulator and the industry still exist even after the divestiture of the physical ties of assets. Thus, not only is regulatory independence undermined but government-business relations become even subtler. Generally speaking, the current institutional environment at both economy and sector levels in China is of an unstable, unpredictable, and dynamic nature.

\subsection{The first Challenge: Joint employment of the ex ante and ex post regulation}

\subsubsection{The newly enacted AML (anti-monopoly law)}

Unlike most developing counties around the world, until now china has not adopted a sector-specific law. The Chinese model of telecommunications regulation therefore provides a unique and interesting case of 'competition regulation without a telecommunication law'. (Tania Voon \& Andrew Mitchell , 2010). In the telecommunications service sector, the general problems of translation are compounded by the fact that China has been in the process of drafting a comprehensive telecommunications law for more than 10 years. The law is repeatedly said to be just around the corner, but it is not yet to materialise. Reasons for the delay may include rivalry between a range of interested ministries, differences of opinion among various stakeholders regarding the appropriate balance between State control and free market principles, In the absence of a telecommunications law, telecommunications in China is governed by a disparate collection of regulations and rules, the operation of which is often uncertain and 'inconclusive'. Importantly, Both the ex ante specific-regulation and the ex post competition policies should operate jointly in the telecommunications industry.

Although a new PRC Anti-Monopoly Law (AML) was enacted on August 30, 2007 and took effect on August 1, 2008, the AML is unlikely to effectively foster competition in China's telecom industry, and Anti-Monopoly conducts are popular in the Chinese telephony. For instance, the three players, even being competitors to each other, in many occasions, could also sit down and discuss the issue of exploring the market place, which further leads the AM to an extensive level. China Telecom taking over China Unicom's CDMA network is such an example. These two companies negotiated a deal of total value of RMB 110 billion and government loan would be the major funding resource for this take over. These are some clear breaches of anti-AM conduct regulated by the new AML especially in its chapter. However, no questions have been asked since the reform took place in May 2008. PRC judiciary has been receiving criticisms in relation to its independence and its decision making power for years. It would be unwise to put hope on the judiciary to change the administrative decisions. The likelihood that the new AML would make changes to the current situation in the PRC's telecommunications market is minimum. This reform indicated a virtualized administrative will in creating an oligopoly telecommunications market with three SOEs. This reform is against the free market competition theories and the Chinese WTO telecommunications commitment. It also undermines the sustainable development of the telecommunications industry in China in the long run. In addition, this situation is unlikely to be changed by any domestic force in the foreseeable future. Thus, the AML is unlikely to effectively foster competition in China's telecom industry. To achieve a healthy and sustainable growth, the PRC telecommunications market and industry has been in great need of a competition law. However, they want the law to be much more fair and equitable. To ensure the confidence of investors in China's telecommunications sector, and to ensure that China continues to develop a transparent, pro-competitive, and effective telecommunications industry, there is much work that the Chinese government needs to complete.

\subsubsection{The difference of the ex ante and ex post regulation}

The present market structure of the telecommunications industry urges some type of control, either by means of sector-specific regulation or by competition policy. Asymmetric ex ante regulation $\rceil$ aims at preventing the incumbent from abusing its dominant position and competition policies provide ex post control. Both measures operate jointly in the telecommunications industry.

Apart from their timing, these two types of control mechanisms differ mainly in two aspects.( Marc Bourreau and Pinar Doan ,2001). First, regulatory authorities and antitrust authorities are distinct as the former hold superior knowledge with regard both to the regulated firm and the regulated industry. In the absence of regulatory bodies, antitrust authorities may be ineffective for gathering all the relevant information.

Another important difference is with respect to the policy objectives of the two control mechanisms. The competitive process is relied upon to provide goods and services at acceptable conditions of price and quality, with only a relatively minimal intervention to correct specific market failures. Traditional regulation, on the other 
hand has been employed to achieve specifically defined social and political objectives, for instance to impose universal service obligations. Achievement of these social and political objectives requires a more rigid intervention. On the contrary, the objective of competition policy is rather an 'unrestricted' one, and can be achieved by more flexible mechanisms. For that reason, control by competition policies provides a certain degree of freedom for the incumbent firm's business decisions. Due to the difference in the degree of control, one might expect a bias towards over-controlling by ex ante control and bias towards under-controlling by ex post control. It may be possible to eliminate these biases by the joint use of the two types of control mechanisms in certain ways.

\subsection{3 'Essential facility' doctrine - effective antitrust tool}

As telecom regulation initially focused mostly on efforts to liberalize markets characterized by the presence of one public or private monopolist, one of the antitrust tools that served regulators' purposes most directly was the 'essential facility' doctrine (Andrea Renda , 2010). The essential facility doctrine lies at the core of telecoms regulation since its very first steps in the United States and in the European Union. Later, the doctrine spread around the world and Competition currently stands as a key pillar of the liberalization efforts underway in several countries. More recently, several other legal systems adopted the essential facilities doctrine as the pivotal tool of their liberalization efforts. This is also due to the incorporation of the concept in the WTO basic negotiation on telecommunications services. Today, Canada, South Africa, Japan, Australia among others refer to this concept as a key element of their regulatory framework for electronic communications. In the case of china, 'essential facility' doctrine should be considered in the future telephony regulation process.

\subsection{The second challenge: building a new legislative culture for the regulator}

\subsubsection{Issues about MIIT's independence and impartiality}

The extensive level of Chinese government involvement in the business of Telecommunications suppliers has the potential to create serious conflicts of interest in MIIT, since the government is at once the regulator, owner and operator of the telecommunications suppliers. In the words of the United States Trade Representative ('USTR'): The fact that the Chinese government owns and controls all major basic service operators in the telecommunications sector and plays an active role in managing the industry's structure continues to raise serious questions about the ability of the regulator to act impartially, as required under China's WTO Reference Paper commitments. The role of MIIT, as China's telecommunications regulator, raises questions about independence and impartiality. Significantly, these obligations focus purely on the independence of the regulator from telecommunications operators (Tania Voon \& Andrew Mitchell, 2010). The WTO rules thus adopt a narrow view of regulatory independence. Broader perspectives of regulatory independence encompass independence from government, independence from industry bodies, and independence from consumers, taking into account factors such as structural independence and financial independence. According to China, its telecommunications regulator has been 'structurally and financially' separate from all telecommunications operators and providers - since the Ministry of Information Industry was established in 1998. However, the distinction between independence from operators and independence from government becomes blurred when the operators are State-owned, as is typically the case in China's telecommunications service industry. China has identified telecommunications as one of seven 'strategically important' sectors that must remain under State control.

China's BTS market is almost entirely occupied by three major suppliers (all offering both fixed line and mobile services and all State-owned): China Mobile Communications Corporation ('China Mobile'), China Telecommunications Corporation ('China Telecom'), and China United Network Communications Group Co. Ltd ('China Unicom'). The State shareholding in these companies is held by the State-owned Assets Supervision and Administration Commission and not by MIIT. Nevertheless, both SASAC and MIIT are intimately involved in the suppliers' operations. Together with the Ministry of Finance and the National Development and Reform Commission, MIIT carved these three major suppliers out of the existing six in 2008 by dictating the sale of China Unicom's CDMA network to China Telecom and the merger of China Netcom with China Unicom, China Satcom with China Telecom, and China TieTong with China Mobile. At the same time, SASAC directed a reshuffling of senior executives across the former six competitors.

\subsubsection{The rising importance of unified regulation}

Recently, The European Commission is at the forefront of developing a new legislative culture. In doing so it not only aims at reducing and simplifying traditional regulative tools such as traditional command-and-control-oriented legislation (e.g., regulations and directives) but also at encouraging alternative modes of legislation, notably self- and co-regulation.( Michael Latzer, Natascha Just, Florian Saurwein and Peter Slominski ,2006). 
In fact, the British experience in establishing the Office of Communications ('OFCOM') has confirmed that the 'one-stop-shop' approach of a unified regulator results in 'clearer accountability', and a 'coordinated public profile'. Moreover, both a unified regulator and unified legislation should promote competition in the local telecommunications market. Evidently, competition in the local communications sectors is regulated by 'sector-specific' laws, which are increasingly ineffective as the broadcasting and telecommunications markets intertwine. For example, anti-competitive practices may arise but their impact can be assessed only if the entire communications sector is treated as a single market. In addition, new opportunities for business synergies will arise in the era of market convergence so that a unified regulator should cope better with 'cross-sectoral' competition in this environment. (Richard W.S. Wu \& Grace L.K. Leung, 2008). There will be a higher consistency in regulatory approach and practices towards local communication industry players, and regulatory expertise can also be pooled to deal with issues arising from convergence. What is more, operational synergy and efficiency can be accomplished by merging the broadcasting and telecommunications regulators into one unified regulator. Therefore, The government proposals for the adoption of both a unified Communications regulator is a desirable reform to promote competition in the local telecommunications sector.

\subsection{The third challenge: using cost observation to regulate telephony}

Through these years regulation reform, China telephony has gain great success, however, some unsolved issues still puzzles the industry, which including the telecom service tariff, the network interconnection ,and the universal services obligation. Generally speaking, the fundamental reasons for these problems lie in the difficulty to measure and calculate the telecommunication services cost. Compared with the western telecom carrier, the Chinese operator still face pressures to provide detailed and true cost information to the Chinese telecom regulator, but the next stage of profound reform necessarily require the operator to supply more accurate and sufficient cost data to the regulator.

Until now, the Chinese telecom pricing still based on the traditional method of "cost plus profit". The information asymmetry between the regulator and operator make the cost calculation a very hard work. Being lack of a proper cost model to support the cost observation, Chinese government set the service tariff randomly and subjectively. According to classical theory, there are two solutions to telecom cost oberservation, the former is cost analysis based on the accounting data, and the latter is to adopt cost agency model based on computer applications. Concerning the accounting data, both the history data and actual data should be considered together to determine the ultimate service cost,

Although the telecom cost model such as LECOM can be an ideal solution to the existed problem, the practices shows the fact the successful application of the model rely on mass data supporting, such as subscriber distributed data, equipment price data, and so on, which makes an significant barrier to the regulator. Besides that, the LECOM model designing requires the engineer have comprehensive and profound knowledges and experiences in both the telecom technology understanding and large scale telecom project reconstruction. All these requirements increase the complexity to the telecom cost testing and forecasting issues for the Chinese regulator.

In recent years, social supervision to the price issues in natural monopoly industry has developed widely, for China, the government implement the public price hearing. But from a practical effect, most of China trial hearings, at least have two flaws: the first one is the lack of extensive and representativeness of the hearing members, the members taking part in the hearings are the officers specified by the competent Department of the Government, as a result, it is difficult to fully represent the interests of the parties in a closed hearing; the second shortcoming is the lack of necessary feedback. In China, social supervision organization is the national consumer association, which is not a professional consumer organization in the natural monopoly industry, this made the telecom price supervision a very hard work without the industry expert's help and suggestions.

\subsection{The forth challenge: using SMP regulation to further improve market competition}

The abbreviation 'SMP' stands for 'Significant Market Power'. The European Commission introduced the concept of Significant Market Power to bring an element of ex ante regulation to competition policy in telecommunications. An operator is presumed to have SMP if it has more than $25 \%$ of a telecommunications market in the geographic area in which it is allowed to operate. The concept of SMP has since been adopted in other jurisdictions. The European Commission defines Significant Market Power as the ability of a firm to act independently of competitors and customers. Under the European model, firms that are found to have SMP are subject to additional ex ante regulatory obligations. This allows telecommunications regulators to impose ex ante regulatory obligations on firms with SMP, such as:

\footnotetext{
- Obligations to align interconnection prices with costs
} 
- Accounting separation requirements

- Mandatory publication of reference interconnection offers.

The EU Commission has already published guidelines for market analysis and establishing significant market power. According to the guidelines, it is necessary to consider whether SMP exists in order to safeguard effective competition. The guidelines state that if no operator with SMP is found in the assessment, competition is effective and the existing SMP remedies are removed and no new ones are imposed. On the other hand, if at least one SMP operator is found, competition is not effective and the necessary obligations will be imposed on the operators. The following criteria must be assessed when determining whether SMP exists:

- Market share

- the economic and financial strength of the operator

- technological superiority

- lack of buyer power on the part of customers or suppliers

- extensive supply selection

- advantages of scale and scope

- vertical integration

- advanced distribution and sales networks

- lack of potential competition

- barriers to the sector

- barriers to expansion

The telephony supervision require professional regulation tools to fulfill effective regulation, SMP obviously play a significant role in the asymmetric regulation from the experiences of many countries practices. Compared with the western countries, China telephony has to accumulate experiences to future improve the regulation of the industry.

\section{Conclusion}

For Chinese telephony, the new restructuring scheme - designed to boost efficiency and create three full-service operators is completed by the end 2008. This paper studies the regulatory trajectory of the telecommunications industry in China. Different stages of the regulation process with policy intervention and market competition are examined. The interaction of different players like the Chinese government, incumbent operator, and competitive operator is analyzed.

In the paper, two general theories of regulation, public interest theory and the economic theory of regulation are firstly introduced. Theses literatures are later used to explain the current regulatory particularities of Chinese telephony. Although, it is obvious that the Chinese telephony reforms itself successfully, however, Convergence happened recently has created a set of new dynamic issues and great challenges in the industry.

\section{References}

Andrea Renda. (2010). Competition-regulation interface in telecommunications: What's left of the essential facility doctrine .Telecommunications Policy, Volume 34, Issues 1-2, February-March 2010, 23-35.

Edward Balleisen \& David Moss. (2009). Government and Markets: Toward A New Theory of Regulation, 2-6.

Eli M. Noama. (2010). Regulation 3.0 for Telecom 3.0. Telecommunications Policy, Volume 34, Issues 1-2, February-March 2010, 4-10.

Grace Li. (2009). Can the PRC'S new anti-monopoly law stop monopolistic activities: Let the PRC'S telecommunications industry tell you the answer. Telecommunications Policy, Volume 33, Issue 7, August 2009, 360-370

Johannes M. Bauer. (2010). Regulation, public policy, and investment in communications infrastructure .Telecommunications Policy, Volume 34, Issues 1-2, February-March 2010, 65-79

John T. Wenders. (1988). The economic theory of regulation and the US telecoms industry. Telecommunications Policy, Volume 12, Issue 1, 16-26

Jun Xia. (2007). Towards a Sustainable Institutional Arrangement for USOs in China: Current Status, Support Mechanisms, and Regulatory Governance. A Journal of Law \& Policy for the Information Society, Vol. 3, No. 3 
Jun Xia and Ting-Jie Lu. (2008). Bridging the digital divide for rural communities: The case of China, Telecommunications Policy, Volume 32, Issues 9-10, October-November 2008, 686-696

Marc Bourreau \& Pinar Doan. (2001). Regulation and innovation in the telecommunications industry. Telecommunications Policy, Volume 25, Issue 3, April 2001, 167-184.

Marc Bourreau and Pinar Doan. (2001). Regulation and innovation in the telecommunications industry. Telecommunications Policy, Volume 25, Issue 3, April 2001, 167-184.

Mark A. Jamison \& Mark A. Jamison (2008). Overview of Infrastructure Regulation. Annotated reading list for a body of knowledge on infrastructure regulation, 3-8.

Michael Latzer, Natascha Just, Florian Saurwein and Peter Slominski (2006). Institutional variety in communications regulation. Classification scheme and empirical evidence from Austria .Telecommunications Policy, Volume 30, Issues 3-4, April-May 2006, 152-170

MII, NDRC \& Treasury. (2008). A notice of deepening reform in telecommunications sector. [Online] Available: http: //www.mii.gov.cn/art/2008/05/24/art_2001_45730.htmlS. (May 25, 2008)

Noam, E. (2006). Fundamental instability: Why telecom is becoming a cyclical and oligopolistic industry. Information Economics and Policy, 18(3), 272-284.

Paul de Bijl \& Martin Peitz. Innovation, convergence and the role of regulation in the Netherlands and beyond. Telecommunications Policy, Volume 32, Issue 11, December 2008, 744-754.

Ping Gao \& Kalle Lyytinen. (2000). Transformation of China's telecommunications sector: a macro perspective. Telecommunications Policy, Volume 24, Issues 8-9, September 2000, 719-730

Richard W.S. Wu \& Grace L.K. Leung. (2008). Competition regulation in the Hong Kong telecommunications sector-Challenges and reforms. Telecommunications Policy, Volume 32, Issues 9-10, October-November 2008, 652-661.

Tania Voon \& Andrew Mitchell. (2010). Open for Business? China's Telecommunications Service Market and the WTO. Journal of International Economic Law, Volume13, Issue2, 321-378. 